PROCEEDINGS OF THE WORLD CONFERENCE ON OZONE THERAPY IN MEDICINE, DENTISTRY AND VETERINARY. ANCONA (ITALY). SEPTEMBER 22nd - 23rd - 24th, 2017

\title{
Medical and technical requirements for medical ozone generator devices [abstract]
}

\section{Valter Travagli}

University of Siena. Italy

\section{ABSTRACT}

\section{OPEN ACCESS}

\section{Citation}

Travagli V. Medical and technical requirements for medical ozone generator devices [abstract]. Proceedings of The World Conference on Ozone Therapy in Medicine, Dentistry and Veterinary. Ancona (Italy). September 22nd - 23rd - 24th , 2017. J Ozone Ther. 2019;3(4):76. doi 10.7203/jo3t.3.4.2019.15548

\section{Academic Editor}

Jose Baeza-Noci,

School of Medicine, Valencia

University, SPAIN

\section{Editor}

World Federation of Ozone Therapy, Bolgna, ITALY

\section{Received}

June 17, 2019

\section{Accepted}

December 08, 2019

Published

December 30, 2019

Intellectual Property

Valter Travagli.

This is an open access article distributed under the terms of the Creative Commons Attribution License (CC BY 4.0), which permits unrestricted use, distribution, and reproduction in any medium, provided the original author and source are credited.

Author Information

valter.travagli@unisi.it
According to the definitions and the scope of both starting material and bulk pharmaceutical product, the achievement of Quality standards is an indispensable guarantee for the safety of use, stability and effectiveness of the medicinal products. Medicinal gases - among which the oxygen-ozone therapy is fully entitled - have to fulfil such a Quality objective.

Moreover, the therapeutic use of ozone assumes the extemporaneous preparation of the gaseous mixture, demanding the overall responsibility to the healthcare professionals. As a result of scientific and technical progress, the ozone generators must be validated having passed all the qualification phases. The relevant EU and FDA Regulations will assure this aspect by the respective conformity marking.

Given that the overall Quality level is given by the lowest stage of the whole process, the knowledge of the various aspects and the respect of welldefined standard operating procedures become fundamental. In detail, for the correct application of ozone therapy they will have to be known the medical and technical requirements relating to:

I. the gaseous source for obtaining medical ozone;

II. the materials adopted for ozone generation as well as for its manipulation;

III. the device of reactors for the ozone production;

IV. the modality of varying the ozone concentration;

V. the control and measuring devices for medical ozone quantitative evaluation, also in terms of their precision and accuracy;

VI. the warranty period and the local maintenance service, also in terms of validation plan.

Based on this knowledge, it is possible to make an informed purchase of the equipment suitable for both the needs of the individual professional and the correct procedures for use. 